\title{
Erratum to: Overall survival and extent of surgery in adult versus elderly glioblastoma patients: A population based retrospective study
}

Iris Zachenhofer, Roland Maier, Helmut Eiter, Martin Muxel, Manfred Cejna, Alexander DeVries, Karl Roessler

Erratum to: Wien Klin Wochenschr

DOI 10.1007/s00508-011-1577-4

It has been brought to our attention that in the publication "Overall survival and extent of surgery in adult versus elderly glioblastoma patients: A population based retrospective study” (Wien Klin Wochenschr 2011; 123 (11-12): 364-368), the co-author Martin Muxel was erroneously printed as „Bernhard Muxel“.

The online version of the original article can be found under

DOI 10.1007/s00508-011-1577-4 